\title{
FILTROS DE ALTA PRESSÃO PARA REJEITOS E CONCENTRADOS*
}

Vinícius de Souza Vilela ${ }^{1}$

\section{Resumo}

O presente trabalho tem por objetivo analisar o uso de filtros de alta pressão no tratamento de polpas decorrentes do beneficiamento mineral, em especial rejeitos e concentrados de mineração. Foram analisados os problemas da atual prática de deposição de finos em barragens de rejeitos e baias de decantação e os novos desafios encontrados pelo setor em relação a escassez de água e eficiência energética. São elencados os diferenciais tecnológicos implementados nos filtros prensa Matec e analisados os benefícios na aplicação desta tecnologia, tais como maior recuperação de água, redução dos impactos ambientais e redução dos custos operacionais para manuseio e disposição dos rejeitos. Por fim são analisados os testes de filtragem realizados com rejeitos e concentrados de minério de ferro.

Palavras-chave: Filtro; Desaguamento; Rejeito; Concentrado.

\section{Abstract}

\section{HIGH PRESSURE FILTERS FOR TAILINGS AND CONCENTRATES}

This study aims to analyze the use of high pressure filters in the treatment of pulps resulting from mineral processing, especially mining tailings and concentrates. The current practice problems of deposition of fines in tailings dams and settling ponds were analyzed, as well as the new challenges faced by the sector in relation to water scarcity and energy efficiency. Are listed technological differentials implemented in Matec filter presses and analyzed the benefits in application of this technology, such as higher water recovery, reduce of environmental impacts and reduce of operating costs for handling and disposal of waste. Lastly, we analyze the filtration tests performed on iron ore tailings and concentrates.

Keywords: Filter; Dewatering; Tailings; Concentrate. 


\section{INTRODUÇÃO}

\subsection{Contextualização}

Os processos de beneficiamento na indústria mineral são, em sua maioria, a úmido. A água é utilizada em diferentes etapas de classificação, concentração, moagem e transporte dos minérios, e sem a qual tais processos se tornariam ineficientes, caros ou até mesmo impossíveis de serem realizados. Finalizada a etapa de beneficiamento, têm-se duas polpas que necessitam ser tratadas: concentrado e rejeito.

Neste trabalho concentraremos nossa análise no beneficiamento de minério de ferro, mas que pode ser facilmente extrapolada para outros tipos de minérios.

\subsection{Prática Atual da Indústria Mineral}

Os concentrados, também chamados de pellet feed, por serem muito finos, não são adequadamente desidratados por peneiras desaguadoras, uma vez que a perda de sólidos no underflow é alta. O mais indicado é a utilização de filtros, para que a perda de partículas sólidas seja a mínima possível, tendo em vista que trata-se de minério já beneficiado e de alto valor agregado. De acordo com Chaves [1], geralmente são usados filtros a vácuo para esta aplicação. Algumas minerações com investimentos reduzidos realizam o desaguamento dos concentrados em baias de drenagem.

Em relação aos rejeitos, a prática atual da indústria é majoritariamente a deposição das lamas em barragens ou baias de decantação. As barragens apresentam um alto investimento inicial, proporcionando todavia um custo operacional relativamente baixo durante sua vida útil. $A$ realização de alteamentos também requer um elevado investimento. As baias de decantação, assim como no caso dos concentrados, requerem baixo investimento inicial, demandando porém um elevado custo operacional com a limpeza, manutenção e transporte da lama decantada para um local adequado para deposição.

\subsection{Visão Geral do Problema}

\subsubsection{Concentrados}

A filtragem a vácuo, embora seja a mais utilizada, possui limitações operacionais especialmente quando se trata de minérios com granulometria mais concentrada nas faixas finas. O elevado consumo energético das bombas de vácuo necesárias e a manutenção complexa elevam os custos operacionais destes equipamentos.

As baias de drenagem, embora sejam de fácil implantação, apresentam alto custo operacional com equipamentos e mão de obra para retirada do produto e manutenção das estruturas; bem como um resultado insatisfatório no que diz respeito à umidade do produto final.

\subsubsection{Rejeitos}

De acordo com Guimarães [2], o aumento do volume de rejeitos gerados nas atividades mineradoras, impulsionado pela explotação crescente de jazidas com mais baixo teor metálico, tem acentuado a necessidade de barragens cada vez maiores para a contenção dos rejeitos. Associado a isso, temos a atual dificuldade no licenciamento de áreas para construção de novas barragens, devido aos riscos 
ambientais, crescente pressão da opinião pública e proximidade cada vez maior de áreas residenciais.

As baias de decantação, por sua vez, são uma alternativa viável apenas para as plantas que possuem baixo volume de geração de rejeitos, e ainda assim apresentam elevado custo de manutenção com o emprego de escavadeiras, pás carregadeiras e caminhões para a limpeza das estruturas e transporte da lama para os locais de deposição.

\subsection{Novos Desafios para o Setor}

Com a estiagem percebida nos últimos anos na região Sudeste do Brasil, o acesso a água tem sido uma preocupação, e novos projetos tem encontrado dificuldades na aquisição de outorga para direito de uso de recurso hídrico.

No Brasil, $70,6 \%$ da energia elétrica é proveniente de geração hidráulica (Balanço Energético Nacional, 2014) [3], e os baixos volumes dos reservatórios podem levar a uma escassez e consequente aumento do custo energético. Desta forma, deve ser considerado como fator decisivo em novos projetos a eficiência energética dos equipamentos utilizados.

\subsection{Objetivos}

Demonstrar os filtros de alta pressão Matec como uma alternativa viável ao tratamento de rejeitos e concentrados para a indústria de beneficiamento mineral.

De acordo com Guimarães [2], as operações de separação sólido-líquido estão usualmente relacionadas com:

- recuperação de água para reutilização no processo;

- adequação do percentual de sólidos da polpa exigida pelas operações unitárias subsequentes;

- redução da umidade dos produtos para transporte e comercialização;

- preparação de rejeitos visando transporte e disposição [2].

Portanto, com o uso dos filtros Matec pretende-se recuperar a máxima quantidade de água para reutilização no processo e reduzir a níveis mínimos a umidade nos concentrados e rejeitos, garantindo o menor custo operacional possível e menor consumo de energia.

\section{MATERIAIS E MÉTODOS}

\subsection{Sistema Matec}

Os sistemas de filtragem Matec são usualmente compostos de:

- Tanque de lama: recebe o rejeito ou concentrado da planta, e o acondiciona para ser posteriormente bombeado ao espessador.

- Bomba submersível: eleva a polpa presente no tanque de lama até o espessador.

- Espessador de Alto Desempenho Matec: combina as funções de espessamento e clarificação, entregando um underflow com 50 a $65 \%$ de sólidos, e um overflow bastante clarificado. Requer uma área relativamente pequena para instalação e não possui partes móveis em seu interior. Sem motores, rake, mancais ou bombas de extração. 
- Bifloc + Doson: Estação de preparação, dosagem e análise automática de floculantes. Mistura o polímero na água, realiza testes de proveta e ajusta automaticamente a dosagem da mistura na lama que entra no espessador.

- Tanque de homogeneização: Recebe a polpa adensada do espessador (underflow) e a mantém homogênea até sua injeção no filtro.

- Bomba centrífuga de alta pressão: Extrai a polpa adensada do tanque homogeneizador e a pressuriza no filtro. É controlada por inversor de frequência.

- Filtro Prensa Matec: Após o fechamento e travamento das placas pelo pistão hidráulico, a polpa é bombeada para dentro do filtro, preenchendo todas as câmaras formadas pela união das placas. A pressão da polpa obriga o filtrado a atravessar os tecidos e escorrer pelos dutos de drenagem, enquanto os sólidos permanecem retidos. Terminado 0 ciclo, interrompe-se 0 bombeamento, as placas são abertas e as tortas descarregadas.

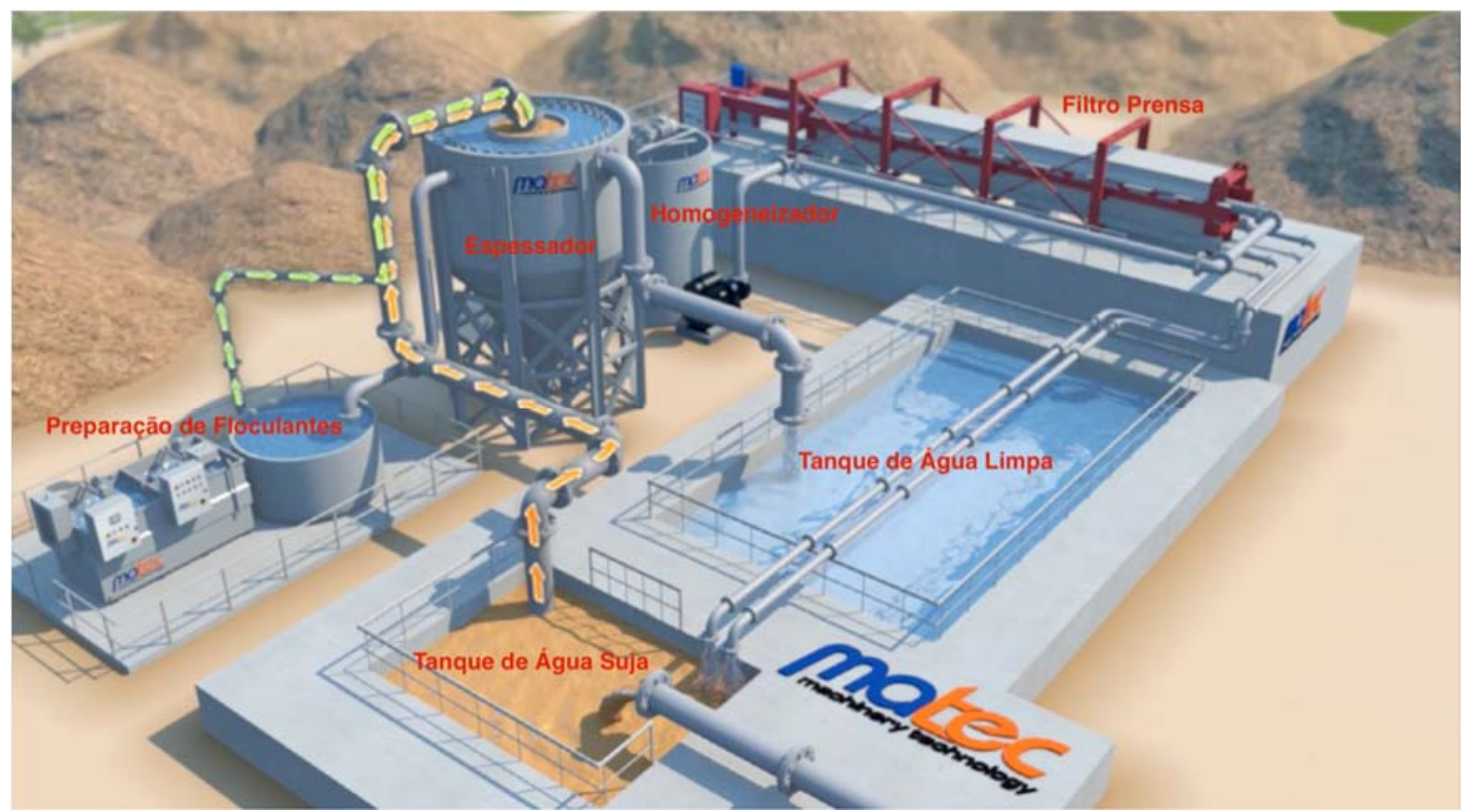

Figura 1. Sistema de espessamento e filtragem MATEC.

Fonte: Matec, 2014

Tecnologias exclusivas dos filtros Matec:

- HPT High Pressure Technology ${ }^{\circledR}$ : os filtros prensa MATEC trabalham em elevadas pressões (16 a 21bar), garantindo máxima recuperação da água, mínima umidade nas tortas e um menor tempo de ciclo. As figuras a seguir mostram o efeito da pressão na desidratação (Figura 2) e no tempo de ciclo (Figura 3) para um dado material. 


\section{Desidratação}

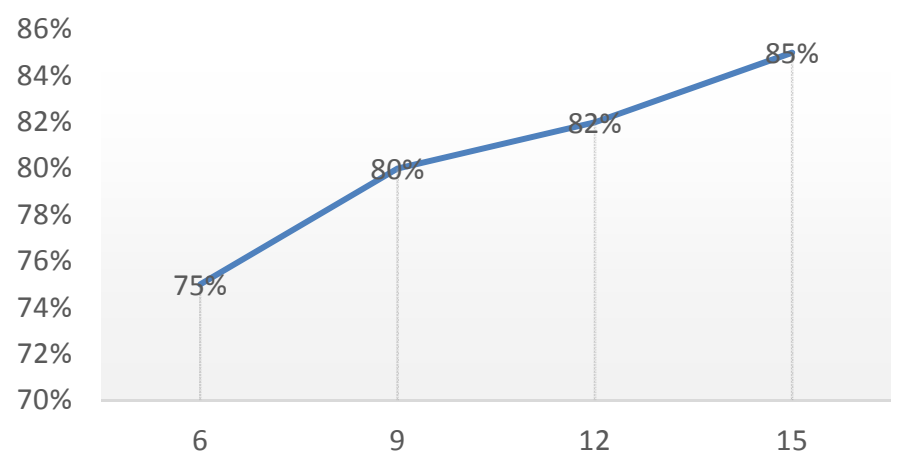

Figura 2. Efeito da pressão (bar) na desidratação da torta. Fonte: Matec, 2012.

\section{Tempo de ciclo ( $\mathrm{min})$}

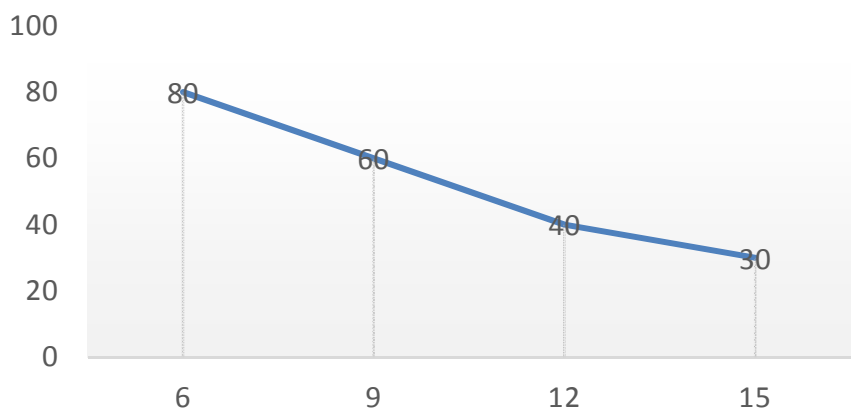

Figura 3. Efeito da pressão (bar) no tempo de ciclo (minutos). Fonte: Matec, 2012.

- TT2 Fast Opening ${ }^{\circledR}$ : sistema de abertura rápida dos filtros, que garante menor tempo improdutivo entre os ciclos, menor tempo total do ciclo e consequentemente mais ciclos por hora e mais produtividade.

São sistemas de operação totalmente automatizada, controlada por PLC e facilmente integrados à planta existente.

\subsection{Planta Piloto}

Para comprovação dos resultados na filtragem de rejeitos e concentrados de minério de ferro, foram realizados testes com uma unidade piloto de filtro prensa, constituída de:

- Bomba de membrana M4x2 com alimentação pneumática nominal 8bar e pressão nominal de saída $16 \mathrm{bar}$.

- Filtro prensa Matec 250/3 (03 placas de $250 \times 250 \mathrm{~mm}$ ), pressão nominal de operação $16 \mathrm{bar}$, espessura da câmara $20 \mathrm{~mm}$. O tecido de filtragem empregado foi poliamida RS 12/12 com permeabilidade de $500 \mathrm{l} / \mathrm{min} / \mathrm{dm}^{2}$. 


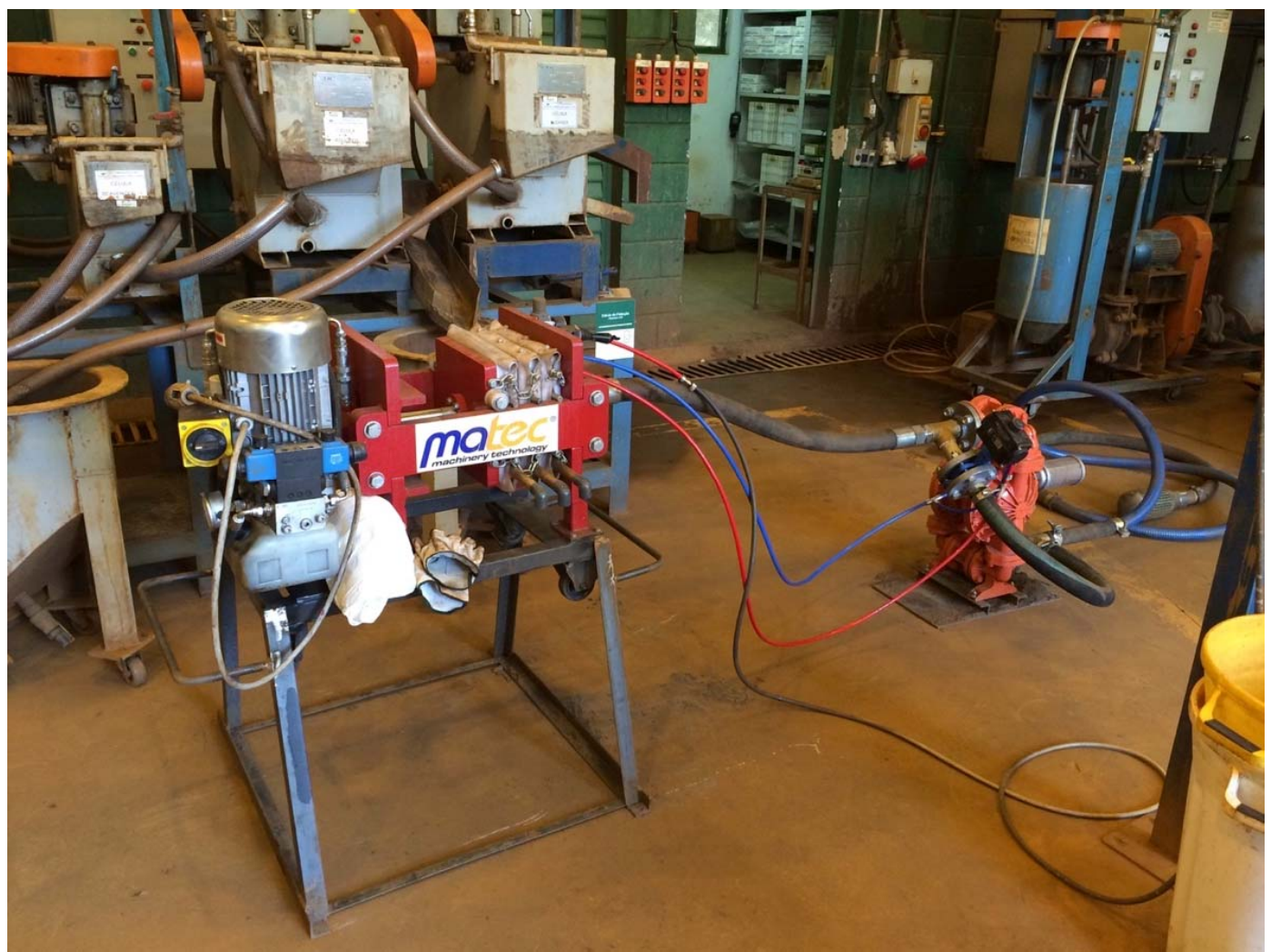

Figura 4. Planta piloto de filtragem.

A polpa já adensada é depositada em um tanque homogeneizador, que mantém as partículas sólidas em suspensão. A bomba succiona esta polpa e a injeta no filtro prensa, que por sua vez retém as partículas sólidas, formando a torta, e descarta a água recuperada (chamada de filtrado) pelos tubos de drenagem.

Para avaliação dos resultados, foram medidos:

- tempos dos ciclo de filtragem

- umidade das tortas recuperadas

- percentual de sólidos presentes no filtrado

\subsection{Amostras}

Foram coletadas amostras de diferentes mineradoras do Quadriláteros Ferrífero para análise.

\subsubsection{Rejeito}

\subsubsection{Amostra 1}

Rejeito de etapas de deslamagem e concentração magnética, combinados.

Percentual de sólidos na polpa: $55 \%$

Densidade real dos sólidos: $3,60 \mathrm{~g} / \mathrm{cm}^{3}$

Densidade da polpa: $1,66 \mathrm{~g} / \mathrm{cm}^{3}$ 
Tabela 1. Distribuição granulométrica da amostra 1.

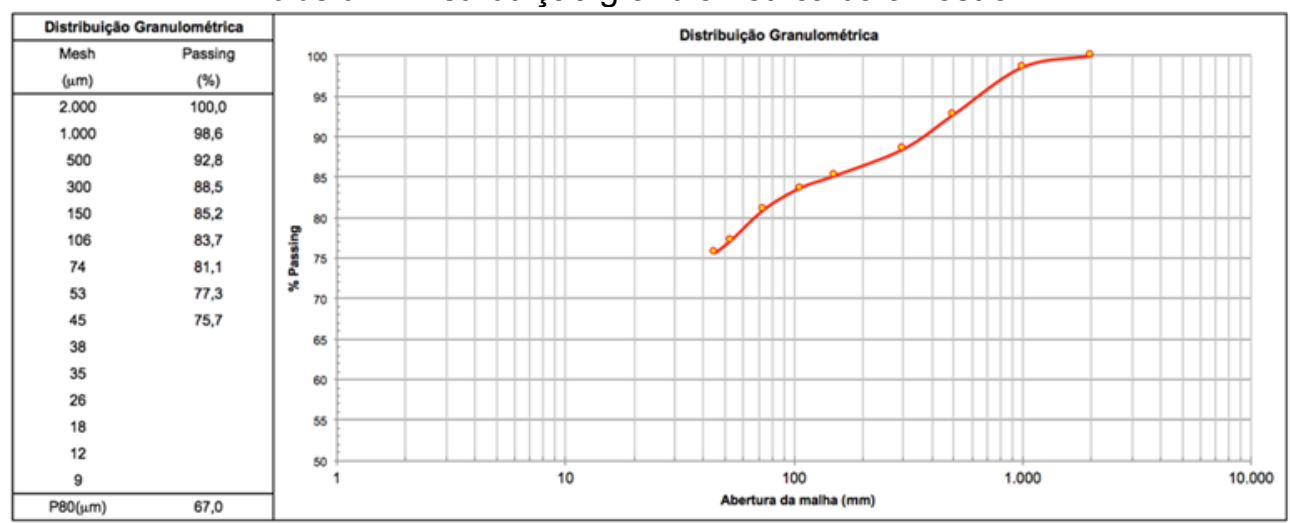

\subsubsection{Amostra 2}

\section{Lamas.}

Percentual de sólidos na polpa: 50,6\%

Densidade real dos sólidos: $3,35 \mathrm{~g} / \mathrm{cm}^{3}$

Tabela 2. Distribuição granulométrica da amostra 2.

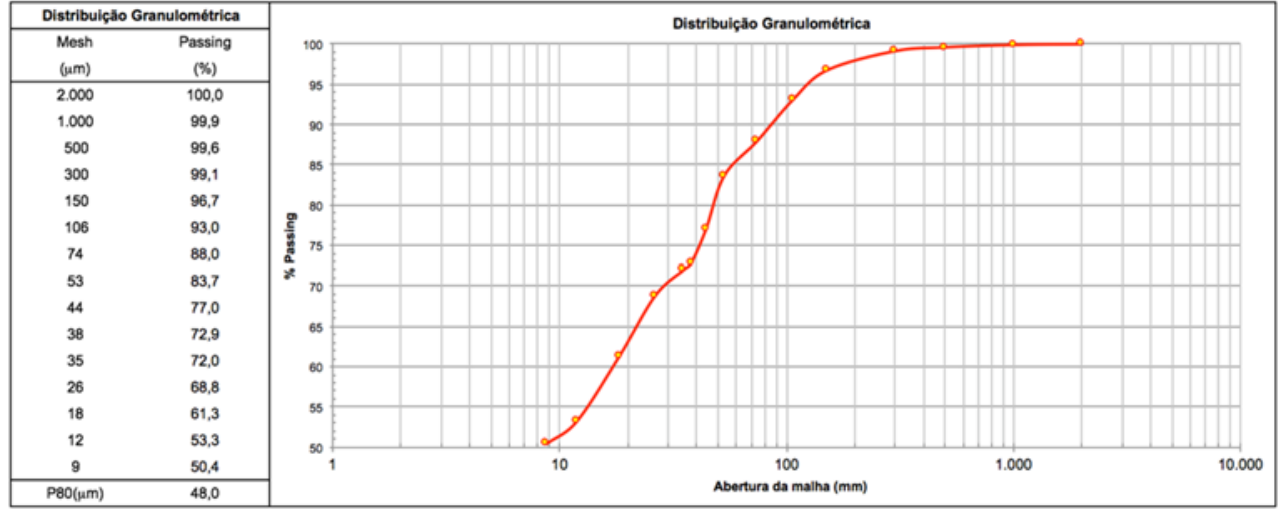

\subsubsection{Amostra 3}

Lamas.

Percentual de sólidos na polpa: $48 \%$

Densidade real dos sólidos: $3,32 \mathrm{~g} / \mathrm{cm}^{3}$

Tabela 3. Distribuição granulométrica da amostra 3.

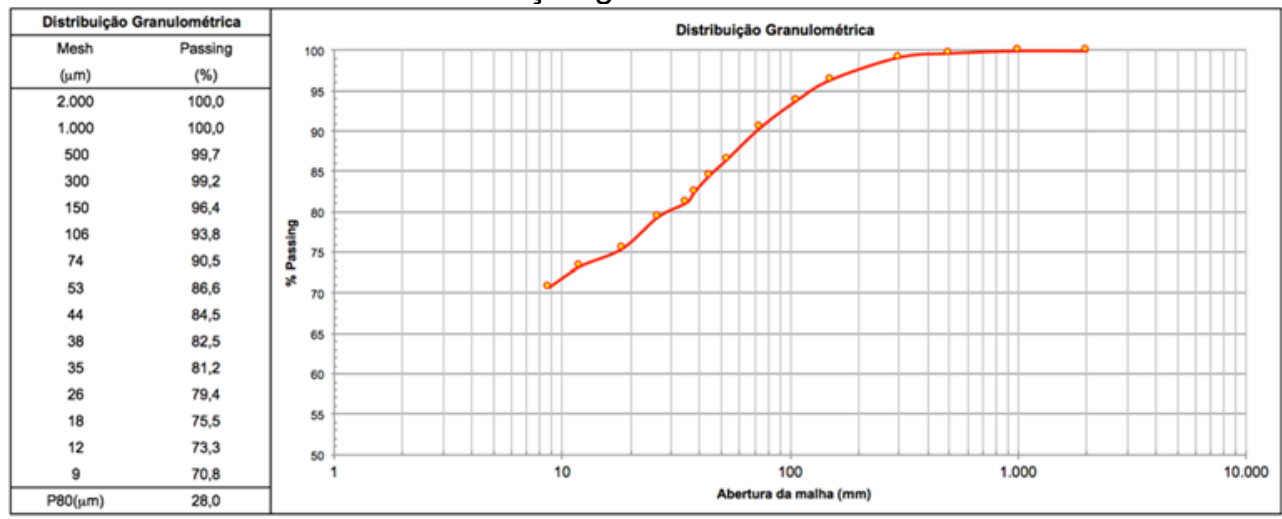




\subsubsection{Concentrado}

\subsubsection{Amostra 4}

Concentrado de minério de ferro resultante de moagem e flotação em colunas (CL, RCL e SCV).

Percentual de sólidos na polpa: $65 \%$

Densidade real dos sólidos: $4,84 \mathrm{~g} / \mathrm{cm}^{3}$

Densidade da polpa: $2,06 \mathrm{~g} / \mathrm{cm}^{3}$

Tabela 4. Distribuição granulométrica da amostra 4.

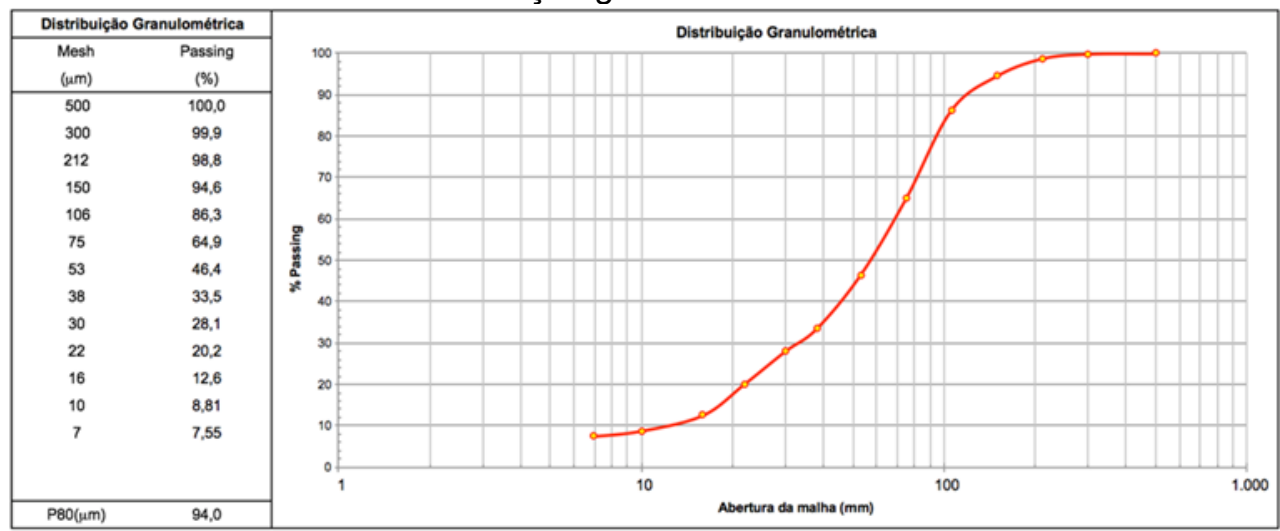

\subsubsection{Amostra 5}

Concentrado de minério de ferro resultante de moagem e flotação em colunas $(\mathrm{CL}$, RCL e SCV).

Percentual de sólidos na polpa: $65 \%$

Densidade real dos sólidos: $4,75 \mathrm{~g} / \mathrm{cm}^{3}$

Densidade da polpa: $2,05 \mathrm{~g} / \mathrm{cm}^{3}$

Tabela 5. Distribuição granulométrica da amostra 5.

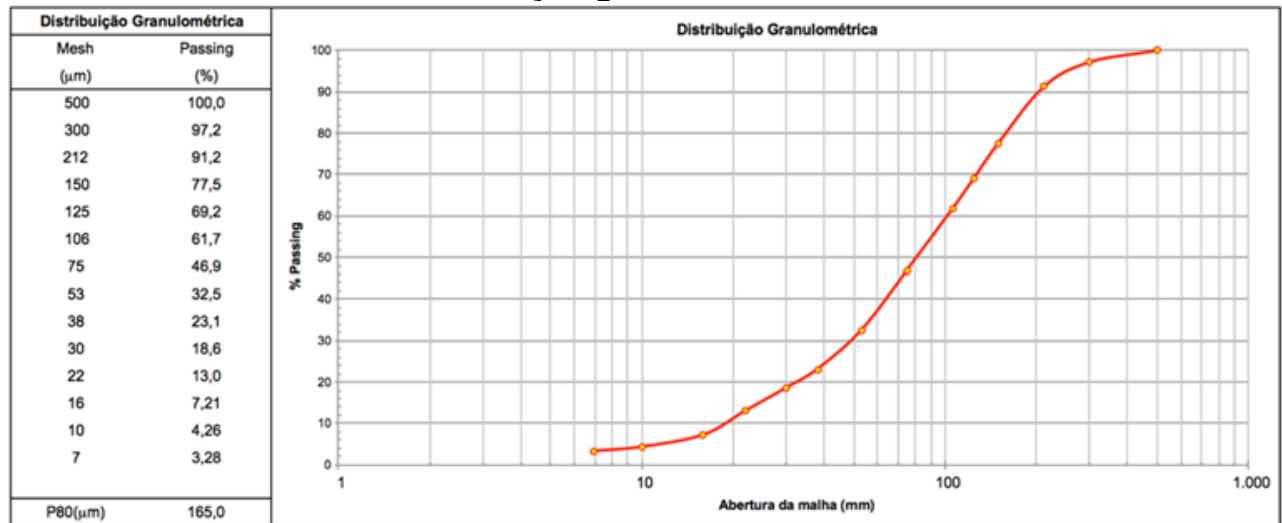

\section{RESULTADOS E DISCUSSÃO}

Os resultados dos tempos de filtragem, umidade das tortas obtidas e percentual de sólidos presentes no filtrado são apresentadas na Tabela 6. 
Tabela 6. Resultados dos testes

\begin{tabular}{cccc}
\hline Amostra & $\begin{array}{c}\text { Tempo } \\
\text { médio } \\
\text { ciclo (min) }\end{array}$ & $\begin{array}{c}\text { Umidade } \\
\text { torta (\%) }\end{array}$ & $\begin{array}{c}\text { \% Sólidos } \\
\text { no filtrado }\end{array}$ \\
\hline 1 & 12 & 13,8 & 1,18 \\
\hline 2 & 15 & 16,4 & 0,62 \\
\hline 3 & 15 & 20,5 & 0,73 \\
\hline 4 & 10 & 12,0 & 2,21 \\
\hline 5 & 12 & 10,3 & 1,08 \\
\hline
\end{tabular}

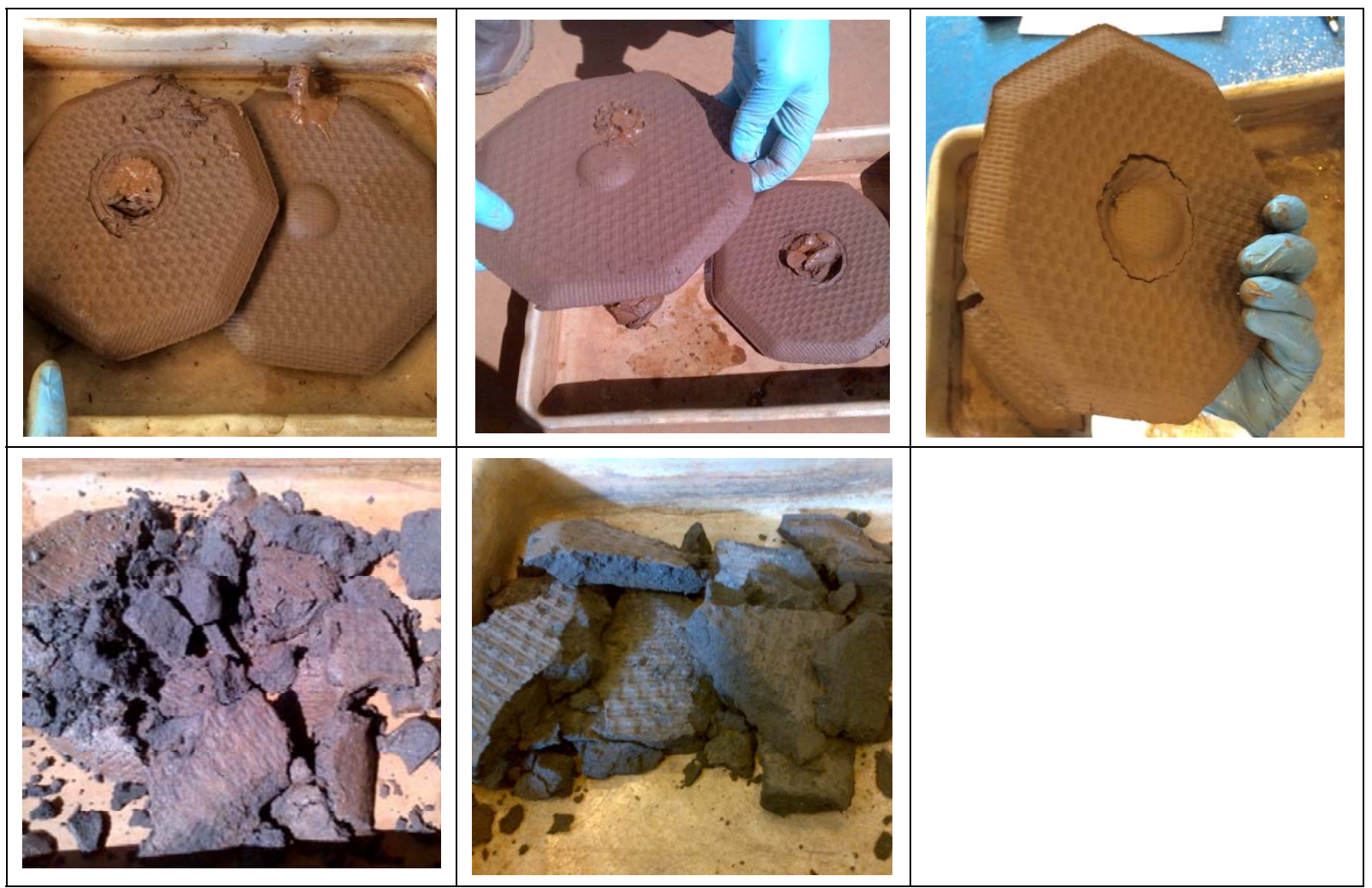

Figura 5. Tortas formadas pela amostras 1, 2, 3, 4 e 5, respectivamente. Da esquerda para a direita, de cima para baixo.

Na Figura 5 podemos ver as tortas formadas por cada uma das amostras. Observase pela análise dos resultados da Tabela 6 que, quanto maior o percentual de finos presente na amostra, maior a dificuldade para se realizar a filtragem e, consequentemente, maior a umidade residual. Estima-se, para todas as amostras analisadas, 3 a 4 ciclos de filtragem por hora em uma operação de escala industrial.

Nenhuma das tortas, de concentrado ou rejeito, apresentou água liberada em seu interior. Embora não tenha sido medido, observou-se nas tortas de rejeito uma alta compactação e resistência mecânica.

Os resultados de umidade residual para filtragem de lamas se assemelham aos obtidos por Guimarães [2], embora a taxa unitária de filtragem não tenha sido avaliada no presente estudo.

\section{CONCLUSÃO}

A filtragem de concentrados e rejeitos de minério de ferro, incluindo lamas, com uso de filtros de alta pressão Matec mostrou-se viável tecnicamente. Para aplicações em escala industrial pode-se ainda recorrer a outros recursos não presentes na planta 
piloto, como sopro no tubo central ao final do ciclo para expulsão da lama, e secagem das tortas por ar comprimido. Com esses recursos adicionais estima-se reduzir em 2 pontos a umidade final.

As tortas de rejeito podem ser disposta em pilhas, mas requerem estudos geotécnicos complementares.

\section{REFERÊNCIAS}

1 Chaves, A. P. Desaguamento, espessamento e filtragem. $4^{a}$ edição. São Paulo: Oficina de Textos, 2013.

2 Guimarães, N. C. Filtragem de rejeitos de minério de ferro visando a sua disposição em pilhas. Dissertação de Mestrado, Universidade Federal de Minas Gerais, Programa de Pós-Graduação em Engenharia Metalúrgica e de Minas, abr. 2011.

3 Empresa Nacional de Pesquisa Energética. Balanço Energético Nacional 2014 Relatório Síntese - ano base 2013. Rio de Janeiro, 2014. 